\title{
Effect of Cyclodextrin Garcinol Complex on Pressure Overload- Induced Cardiotoxicity and Cardiac Hypertrophy by Aortic Stenosis in Rats
}

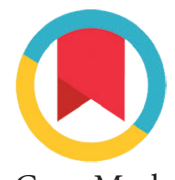

\author{
Shiv Kumar Kushawaha, ${ }^{1}$ Prasad Thakurdesai, ${ }^{2}$ Vishwaraman Mohan, ${ }^{2}$ \\ Subhash L. Bodhankar ${ }^{3 *}$
}

ABSTRACT

Background: Garcinol is a polyisoprenylated benzophenone derived from rinds of fruit of Garcinia species namely Garciniaindica (common name 'Kokum) and Garcinia cambogia (common name 'Gombogee). Garcinol is not stable and has poor bioavailability which can be improved by complexing garcinol with cyclodextrin (cyclodextringarcinol complex).

Objective: The objective of the present study was to investigate effect of cyclodextrin-garcinol complex $(20 \mathrm{mg} / \mathrm{kg} /$ ) on pressure overloadinduced cardiotoxicity and cardiac hypertrophy by aortic stenosis in rats. Methods: Male Wistar rats (250-300g) were divided into following four groups such as: control, sham, stenosis and cyclodextrin-garcinol complex. Daily body weights were recorded. Cyclodextrin-garcinol complex (20 mg/kg/day) in distilled water, was administered orally to rats daily for 18 days and then the animals underwent surgery with aortic binding, the treatment was continued up to 4-6 weeks.
Haemodynamic changes and electrocardiogram (ECG) were recorded in anaesthetized rats.

Results: Pressure overload induced by arotic stenosis in rat resulted in significant myocardial hypertrophy and decreased endogenous antioxidants when compared with the control and sham group animals. Cyclodextrin-garcinol complex (20 mg/kg) showed significant cardioprotective activity by lowering the myocardial hypertrophy, level of lipid peroxidation (MDA content) as well as elevated the level of GSH. The results suggest pre-treatment of cyclodextrin-garcinol complex ( $20 \mathrm{mg} / \mathrm{kg})$, may offer potential benefits in the management of cardiotoxicity and cardiac hypertrophy.

Conclusion: It is concluded that cyclodextrin-garcinol complex (20 mg/kg) protected the haemodynamics of stenosized heart of rats by reduction of lipid peroxidation and preservation of endogenous antioxidants in rat heart.

Keywords: Antioxidants, Cardiac hypertrophy, cyclodextrin-garcinol Complex (20 mg/kg), Aortic Stenosis.

*Correspondence to:

Dr. Subhash L. Bodhankar, Professor of Pharmacology, Poona College of Pharmacy, Bharati Vidyapeeth Deemed University, Pune, India. sbodh@yahoo.com

Cite This Article: Kushawaha, S.K., Thakurdesai, P., Mohan, V., Bodhankar, S.L. 2018. Effect of Cyclodextrin Garcinol Complex on Pressure Overload-Induced Cardiotoxicity and Cardiac Hypertrophy by Aortic Stenosis in Rats. Diabesity 4(2): 17-24. DOI: 10.15562/ diabesity.2018.XXX

\section{INTRODUCTION}

Increased cardiovascular mortality is a serious problem in modern societies. Minimizing the risk of cardiac disease and alleviating the complications of cardiovascular dysfunction are the main therapeutic aim in modern medicine. ${ }^{1}$ Our understanding of the mechanisms of pathophysiology of cardiovascular diseases has been gaining significant advances and a wealth of knowledge implicates sustained overload pressure and oxidative stress as a key causative agent.

Small animal models are the most preferred tools for the study of chronic changes in the development of cardiac hypertrophy. ${ }^{2}$ Constriction of the ascending aorta is one of the most common and successful surgical models for creating pressure overload. ${ }^{3}$

Clinically occurrence of chronic pressure overload is a recurrent that leads to left ventricular hypertrophy (LVH). Initially, LVH was considered to be a compensatory mechanism that allows the generation of the required cardiac output and normalization of wall mechanical stress. ${ }^{4}$ Therefore, aortic stenosis-induced LVH and persistence systemic hypertension can become maladaptive and herald the onset of heart failure. ${ }^{5}$ In rats, gradual aortic constriction for four to eight weeks has been reported to produce stable LV hypertrophy. ${ }^{6}$

The literature shows that in the heart, Ang II (Angiotensin-II) is playing a crucial factor in the development of cardiac fibrosis via collagen disposition and induction of fibroblast proliferation leads to progress of cardiac cell hypertrophy.?

It is reported that in vitro acute release of Ang II within 10 min and the expression of AGT gene (Angiotensin) after $6 \mathrm{~h}$ from cardiomyocytes is induced by the mechanical stretch. ${ }^{8}$ It also showed that Ang II acts as an initial mediator of the stretchinduced hypertrophic response.

Angiotensin II acts via AT1 receptorIfor inducing cardiac hypertrophy. Which is associated with increased expression of many immediate-early

\footnotetext{
'Department of Pharmacology, Laureate Institute of Pharmacy, Kathog, Jawalaji, Kangra. Himachal Pradesh, India.

${ }^{2}$ Indus Biotech Private Limited, off Salunke Vihar Road, Kondhwa, Pune, India.

${ }^{3}$ Department of Pharmacology, Poona College of Pharmacy, Bharati Vidyapeeth Deemed University, Pune, India.
} 
genes (c-fos, c-jun, junB, Egr-1, and c-myc) and fetal marker genes of cardiac hypertrophy (ANF, skeletal $\alpha$-actin, $\beta$-MHC) conferring a pathological phenotype. ${ }^{9,10}$

Additional evidence suggests that phosphorylated Akt/glycogen synthase kinase $3 \beta$ (GSK3 $\beta$ ), extracellular signal-regulated kinases 1 or 2 (ERK1/2) and GATA binding protein 4 (GATA4) pathways play important roles in the process of cardiac hypertrophy and ventricular remodeling induced by pressure overload. ${ }^{11,12}$ All these alterations lead to a worsening of cardiac function, associated with diminished contractility.

The literature shows that chalcones having antioxidant, anti-inflammatory and ACE inhibitor property can reverse the pressure overload induced hypertrophy produced by arotic stenosis, pathogenic conditions and sedentary life style. Garcinol is a polyisoprenylated benzophenone derived rinds fruit of Garcinia species namely Garciniaindica (common name 'Kokum') and Garcinia cambogia (common name 'Gombogee'). It is a potent antioxidant has a limitation of poor stability and bioavailability. ${ }^{13}$ There are several methods to improve these limitations and complexation is one of them.

Literature shows that cyclodextrin is a ( $\alpha-1$, 4)-linked $\alpha$-D-glucopyranose unit, which is able to form inclusion complexes with many drugs by taking up the drug molecule into the central cavity. No covalent bonds are formed or broken during complex formation. The complexed drug molecule remains in rapid equilibrium with free solvated and complexed forms in the solution. The complexation of garcinol with cyclodextrin is reported in literature. Cyclodextrin enhances the drug permeability by direct action on the biological membrane. It also increases the garcinol stability by restricting the drug solvent interaction. The overall result is increased bioavailability. ${ }^{14}$

The aim of present study was to investigate effect of cyclodextrin garcinol complex (cyclodextrin-garcinol complex) on the pressure over induced cardiotoxicity and cardiac hypertrophy by stenosis in rats with a purpose to assess its cardioprotective effect.

\section{MATERIALS AND METHODS}

\section{Material}

The animals were housed under standard housing conditions of temperature $\left(25^{\circ} \mathrm{C}\right)$, relative humidity $(60 \%)$ and photo period of $12 \mathrm{~h}$ dark/12 h light. Pellet diet (Chakan Oil Mills, Pune, India) and water were provided ad libitum. Male Wistar albino rats (250-300 g) were obtained from National Toxicological Centre (NTC) Pune. The Institutional
Animal Ethics Committee (IAEC) 'approved protocols of animal experiments.

\section{Chemicals and sample}

Cyclodextrin-garcinol complex was obtained as gift sample from Indus Biotech Private Limited, Pune, Epinephrine hydrochloride, and malondialdehyde were purchased from Sigma Chemical Co., USA. Reduced glutathione (GSH), 5,5'-dithiobis (2-nitro benzoic acid) (DTNB) and thiobarbituric acid (TBA) were obtained from Hi media, India. All chemicals used were of analytical grade.

\section{Procedure}

Abdominal aortic coarctation was carried out as described by Cordelia et al (2007). ${ }^{15}$ Rats were anesthetized with thiopental $25 \mathrm{mg} / \mathrm{kg}$ (i.p.). Under sterile conditions, the skin was cut open along the abdominal midline. Aortic constriction was created via a left thoracotomy by placing a ligature using sterilized silk suture of size 4-0 (purchased locally from Pune). After that a $40 \mathrm{~mm}$ long cannula of diameter $0.9 \mathrm{~mm}$ was placed longitudinally in the aorta \& tied loosely with it. Then cannula was slowly removed, leaving an aortic lumen of $0.9 \mathrm{~mm}$ diameter. The skin was then closed by stitching. The presence of the ascending aortic constriction precludes left ventricular catheterization by a carotid approach in this model.

Male Wistar rats (250-300g) were divided into following 4 groups. Group1 was control (pre-treated with vehicle i.e. cyclodextrin for 18 days then treatment was continued up to 4-6 weeks). Group 2 was Sham (pre-treated with vehicle i.e. cyclodextrin for 18 days \& then under went surgery without aortic banding, treatment was continued up to 4-6 weeks). Group 3 was stenosis (pre-treated with vehicle i.e. cyclodextrin for 18 days \& then underwent surgery with aortic banding, treatment was continued up to 4-6 weeks). Group 4 was cyclodextrin-garcinol complex (pre-treated with, cyclodextrin-garcinol complex $20 \mathrm{mg} / \mathrm{kg} /$ day for 18 days \& then underwent surgery with aortic banding, treatment was continued up to 4-6 weeks). Daily body weights were recorded.Cyclodextrin-garcinol complex (20 mg/kg/day) in distilled water was administered orally to group 4 rats daily for 18 days then treatment was continued up to 4-6 weeks. On the basis of previous pilot study the dose was selected. The literature showed that the therapeutic potential of the cyclodextrin-garcinol complex at a dose of $20 \mathrm{mg} / \mathrm{kg}$ is comparable to that of administration of $100 \mathrm{mg} / \mathrm{kg}$ (p.o.) of garcinol. ${ }^{16}$ It confirms that the chemically cyclodextrin-garcinol complex increases its therapeutic index by making it more efficacious. Moreover, this activity of cyclodextrin-garcinol 
complex was achieved without any mortality of the animals indicating elimination of toxicity.

The rats were anaesthetized by anesthetic ether. The ECG, heart rate and blood pressure were recorded using 8 channels Power Lab System (AD Instruments Pvt. Ltd., Unit 13, 18-22 Lexington Drive, Bella Vista NSW 2153, Australia).The animals were sacrificed with overdose of thiopental. Randomly hearts from animals were selected for tissue parameter measurement. The heart of each animal was cut in to small pieces, placed in chilled $0.25 \mathrm{M}$ sucrose solution and blotted on a filter paper. The tissues were homogenized in $10 \%$ chilled Tris hydrochloride buffer (10mM, pH 7.4) by tissue homogenizer (Remi Motors, Mumbai, India) and centrifuged at $7500 \mathrm{rpm}$ for 15 minutes at $0^{\circ} \mathrm{C}$ using Eppendorf 5810-R high speed cooling centrifuge. The clear supernatant was used for the measurement of GSH and MDA content.

\section{Tissue parameters Lipid peroxidation assay (MDA content)}

Lipid peroxidation was evaluated by the production of thiobarbituric acid-reactive substances (TBARS). ${ }^{17}$ To $2.0 \mathrm{ml}$ of the tissue homogenate (supernatant) was added to $2.0 \mathrm{ml}$ of freshly prepared $10 \% \mathrm{w} / \mathrm{v}$ trichloroacetic acid (TCA). The mixture was allowed to stand for 15 minutes in an ice bath, followed by centrifugation at $2500 \mathrm{rpm}$ for 10 minutes at $0^{\circ} \mathrm{C}$. Then $2.0 \mathrm{ml}$ of freshly prepared $0.67 \% \mathrm{w} / \mathrm{v}$ thiobarbituric acid was mixed with $2.0 \mathrm{ml}$ of clear supernatant solution. The resulting solution was heated in boiling water bath for 10 minutes. It was immediately placed for 5 minutes in ice bath to cool the solution. The absorbance of colour developed was measured against reagent blank by UV/VIS spectrophotometer (JASCO-V-530, Japan) at $532 \mathrm{~nm}$ using 1, 1, 3, 3-tetraethoxypropane as a standard.

\section{Measurement of GSH}

GSH was estimated by method of Moron et al(1979).$^{18}$ Firstly, $1.0 \mathrm{ml}$ of tissue homogenate (supernatant) and $1 \mathrm{ml}$ of $20 \%$ trichloroacetic acid (TCA) were mixed. It was centrifuged at $2500 \mathrm{rpm}$ for 15 minutes at $0^{\circ} \mathrm{C}$. After that to $25 \mathrm{ml}$ of supernatant, $2 \mathrm{ml}$ of 5, 5' -dithiobis (2-nitro benzoic acid) $(0.6 \mathrm{M})$ reagent was added. The final volume was made up to $3 \mathrm{ml}$ with phosphate buffer ( $\mathrm{pH} 8.0$ ). The colour developed was read at $412 \mathrm{~nm}$ against reagent blank. The amount of reduced glutathione was expressed as $\mu \mathrm{g}$ of GSH /gm of protein.

\section{Determination of organ weight ratio}

Body weight was recorded before sacrifice of animal. Heart weight was recorded after keeping the heart in cold saline and squeezing out the blood followed by drying on tissue paper. The weight of left ventricle was recorded. The left ventricular weight/body weight ratio was calculated.

\section{Statistical analysis}

The statistical analysis was performed by 'Graph pad prism' software. All values were expressed as mean \pm SEM. One way ANOVA was applied to test the significance of biochemical data of different groups and multiple comparisons were determined by the Bonferroni Post hoc test. $\mathrm{P}<0.05$ was considered statistically significant.

\section{RESULTS}

\section{Effect of cyclodextrin-garcinol complex on Systolic BP and Diastolic BP $(\mathrm{mmHg})$ in male Wistar rats}

The Systolic BP (SBP) was significantly $(\mathrm{p}<0.01)$ reduced in the stenosis group compared with normal group or sham. The diastolic BP (DBP) was significantly $(\mathrm{p}<0.01)$ reduced in the stenosis group compared with normal group and Sham. Pretreatment for 18 days and post stenosis treatment for 28 days with cyclodextrin-garcinol complex $(20 \mathrm{mg} / \mathrm{kg})$ resulted in significant $(\mathrm{p}<0.05)$ decrease in systolic where as non- significant decrease in diastolic BP was non-significant in rats (Table 1).

Table 1 Effect of cyclodextrin-garcinol complex on myocardial SBP and DBP

\begin{tabular}{lcccc}
\hline Enzyme & Control group & Sham group & Stenosis group & $\begin{array}{r}\text { Cyclodextrin-garcinol } \\
\text { complex (20 mg/kg) group }\end{array}$ \\
\hline Systolic BP (mmHg) & $86.36 \pm 2.2$ & $81.75 \pm 2.6 \mathrm{~ns}$ & $115.72 \pm 6.3 \# \#$ & $95.612 \pm 2.2^{*}$ \\
$\begin{array}{l}\text { Diastolic BP } \\
\text { (mmHg) }\end{array}$ & $74.31 \pm 2.47$ & $64.80 \pm 6.48 \mathrm{~ns}$ & $94.03 \pm 3.48 \# \#$ & $79.93 \pm 3.48 \mathrm{~ns} 1$ \\
\hline
\end{tabular}

\footnotetext{
SBP- Systolic blood pressure, DBP- Diastolic blood pressure

$(\mathrm{n}=8)$, data are mean $(\mathrm{SEM})]$

ns- non significantas compared with control group

\#\# $\mathrm{p}<0.01$ significant as compared with control and sham group,

${ }^{*} \mathrm{p}<0.05$ significant as compared with stenosis group.

\#\# $\mathrm{p}<0.01$ significant as compared with control and sham group,

ns1-
} 
Table 2 Effect of cyclodextrin-garcinol complex on myocardial MABP

\begin{tabular}{lcccc}
\hline Enzyme & Control group & Sham group & Stenosis group & $\begin{array}{c}\text { Cyclodextrin-garcinol } \\
\text { complex (20 mg/kg) group }\end{array}$ \\
\hline MABP $(\mathrm{mmHg})$ & $77.994 \pm 4.58$ & $70.45 \pm 4.58 \mathrm{~ns}$ & $101.40 \pm 4.06 \# \#$ & $91.128 \pm 3.04 \mathrm{~ns} 1$ \\
\hline
\end{tabular}

MABP- Mean arterial blood pressure

$(\mathrm{n}=8)$, data are mean $(\mathrm{SEM})]$

ns- non significant as compared with control group

\#\# $\mathrm{p}<0.01$ significant as compared with control and sham group,

non significant as compared with stenosis group.

\section{Table 3 Effect of cyclodextrin-garcinol complex on heart rate of rats}

\begin{tabular}{|c|c|c|c|c|}
\hline Ratio & Control group & Sham group & Stenosis group & $\begin{array}{c}\text { Cyclodextrin-garcinol } \\
\text { complex ( } 20 \mathrm{mg} / \mathrm{kg}) \text { group }\end{array}$ \\
\hline $\begin{array}{l}\text { Heart rate } \\
\text { (beats/min) }\end{array}$ & $4.583 \pm 7.413$ & $-13.05 \pm 12.8 \mathrm{~ns}$ & $-88.79 \pm 12.31 \# \# \#$ & $-45.64 \pm 4.673^{\star}$ \\
\hline
\end{tabular}

$[(\mathrm{n}=8)$, data are mean $(\mathrm{SEM})]$

ns non significant compared with control group

\#\#\# $\mathrm{p}<0.001$ significant as compared with control and sham group,

${ }^{\star} \mathrm{p}<0.05$ significant as compared with stenosis group.

Table 4 Effect of cyclodextrin-garcinol complex on ECG of rats

\begin{tabular}{lcccc}
\hline Interval & $\begin{array}{c}\text { Control group } \\
(\mathbf{m s e c})\end{array}$ & $\begin{array}{c}\text { Sham group } \\
(\mathbf{m s e c})\end{array}$ & $\begin{array}{c}\text { Stenosis group } \\
(\mathbf{m s e c})\end{array}$ & $\begin{array}{c}\text { Cyclodextrin-garcinol complex } \\
(\mathbf{2 0} \mathbf{~ m g} / \mathbf{k g}) \mathbf{g r o u p}(\mathbf{m s e c})\end{array}$ \\
\hline QT & $-0.0012 \pm 0.00067$ & $-0.0011 \pm 0.0009 \mathrm{~ns}$ & $0.0187 \pm 0.001 \# \# \#$ & $0.0067 \pm 0.0017^{\star * *}$ \\
ST & $-0.0011 \pm 0.002$ & $-0.0024 \pm 0.002 \mathrm{~ns}$ & $0.014 \pm 0.0017 \# \# \#$ & $0.006 \pm 0.002 *$ \\
\hline
\end{tabular}

$[(\mathrm{n}=8)$, data are mean $(\mathrm{SEM})]$

ns non significant compared with control group

\#\#\# $\mathrm{p}<0.001$ significant as compared with control and sham group,

${ }_{* * *} \mathrm{p}<0.001$ significant as compared with stenosis group.

\#\#\# $\mathrm{p}<0.001$ significant as compared with control and sham group,

${ }^{\star} \mathrm{p}<0.05$ significant as compared with stenosis group.

Table 5 Effect of cyclodextrin-garcinol complex on heart to body weight ratio of rats

\begin{tabular}{|c|c|c|c|c|}
\hline Ratio & Control group & Sham group & Stenosis group & $\begin{array}{c}\text { Cyclodextrin-garcinol } \\
\text { complex }(20 \mathrm{mg} / \mathrm{kg}) \text { group }\end{array}$ \\
\hline $\begin{array}{l}\text { Heart to body } \\
\text { weight } \mathrm{mg} / \mathrm{g}\end{array}$ & $3.135 \pm 0.078$ & $2.985 \pm 0.0769 \mathrm{~ns}$ & $4.085 \pm 0.037 \# \# \#$ & $3.42 \pm 0.0486^{\star \star *}$ \\
\hline
\end{tabular}

$[(\mathrm{n}=8)$, data are mean $(\mathrm{SEM})]$

ns non significant compared with control group

$\# \#$ \# $<0.001$ significant as compared with control and Sham group,

${ }^{* * *} \mathrm{p}<0.001$ significant as compared with Stenosis group.

Table 6 Effect of cyclodextrin-garcinol complex on left ventricular weight to body weight ratio of rats

\begin{tabular}{|c|c|c|c|c|}
\hline Ratio & $\begin{array}{c}\text { Control group } \\
(\mathrm{mg} / \mathrm{g})\end{array}$ & $\begin{array}{l}\text { Sham group } \\
(\mathrm{mg} / \mathrm{g})\end{array}$ & $\begin{array}{c}\text { Stenosis group } \\
(\mathbf{m g} / \mathbf{g})\end{array}$ & $\begin{array}{l}\text { Cyclodextrin-garcinol } \\
\text { complex }(20 \mathrm{mg} / \mathrm{kg}) \text { group }\end{array}$ \\
\hline $\begin{array}{l}\text { Left ventricular to } \\
\text { body weight } \mathrm{mg} / \mathrm{g}\end{array}$ & $1.516 \pm 0.023$ & $1.569 \pm 0.0305 \mathrm{~ns}$ & $1.968 \pm 0.0324 \# \# \#$ & $1.711 \pm 0.0312^{\star * *}$ \\
\hline
\end{tabular}

$[(\mathrm{n}=8)$, data are mean $(\mathrm{SEM})]$

ns non significant compared with control group

\#\#\# $\mathrm{p}<0.001$ significant as compared with control and sham group,

${ }^{* * *} \mathrm{p}<0.001$ significant as compared with stenosis group. 
Table 7 Effect of cyclodextrin-garcinol complex on myocardial MDA and GSH levels

\begin{tabular}{lcccc}
\hline Enzyme & Control group & Sham group & Stenosis group & $\begin{array}{c}\text { Cyclodextrin-garcinol } \\
\text { complex (20 mg/kg) group }\end{array}$ \\
\hline $\begin{array}{l}\text { MDA, nM/mg } \\
\text { protein }\end{array}$ & $2.729 \pm 0.1250$ & $3.399 \pm 0.2121 \mathrm{~ns}$ & $4.546 \pm 0.1797 \# \# \#$ & $3.458 \pm 0.9755^{\star *}$ \\
GSH, $\mu \mathrm{g} / \mathrm{mg}$ protein & $30.39 \pm 1.605$ & $26.09 \pm 0.6497 \mathrm{~ns}$ & $18.73 \pm 0.7187 \# \#$ & $25.53 \pm 1.700^{\star}$ \\
\hline
\end{tabular}

MDA- malondialdehyde, GSH- glutathione.

$[(\mathrm{n}=8)$, data are mean $($ SEM $)]$

ns non significant compared with control group

\#\#\# $\mathrm{p}<0.001$ significant as compared with control and sham group,

${ }^{* *} \mathrm{p}<0.01$ significant as compared with stenosis group.

$\# \#$ $\mathrm{p}<0.001$ significant as compared with control and sham group

${ }^{*} \mathrm{p}<0.05$ significant as compared with stenosis group,
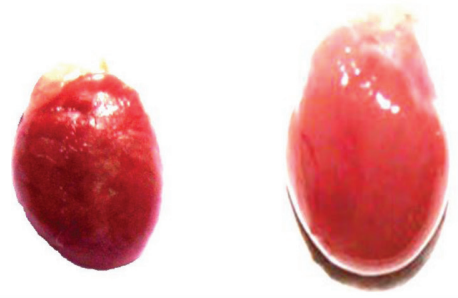

\begin{tabular}{|l|}
\hline Rat heart without aortic \\
stenosis \\
Sham group \\
H.wt $-804.3 \mathrm{mg}$, animal \\
wt-284g
\end{tabular}

\begin{tabular}{|l|l|}
$\begin{array}{l}\text { Rat heart with aortic } \\
\text { stenosis } \\
\text { stenosis group } \\
\mathrm{H} \text { wt- } 1219.5 \mathrm{mg} \text {, animal heart with aortic stenosis } \\
\text { wt-289g }\end{array}$ & cyclodextrin-garcinol Complex group \\
\hline
\end{tabular}

Figure 1 Effect of Cyclodextrin-garcinol complex $(20 \mathrm{mg} / \mathrm{kg})$ on heart weight in rats in experimentally induced cardiac hypertrophy by rat aortic stenosis.

\section{Effect of garcinol complex on MABP $(\mathrm{mmHg})$ in male Wistar rats}

The mean arterial blood pressure (MABP) was significantly $(\mathrm{p}<0.01)$ reduced in the stenosis group compared with normal group or sham). Pretreatment for 18 days and post stenosis treatment for 28 days with garcinol complex $(20 \mathrm{mg} / \mathrm{kg}$ ) resulted in non-significant increase in the MABP as compared with stenosis group in male wistar rats (Table 2).

\section{Effect of cyclodextrin-garcinol complex $(20 \mathrm{mg} / \mathrm{kg})$ on heart rate of male Wistar rats}

Heart rate was significantly $(\mathrm{p}<0.001)$ higher in the stenosis group compared with the control group and sham group Pretreatment for 18 days and post stenosis treatment for 28 days with cyclodextrin-garcinol complex $(20 \mathrm{mg} / \mathrm{kg})$ resulted insignificant $(\mathrm{p}<0.05)$ reduction in heart rate as compared with stenosis group (Table 3 ).

\section{Effect of cyclodextrin-garcinol complex on electrocardiograph of rats}

The mean (SEM) QT interval was significantly $(p<0.001)$ higher in the stenosis group compared with the control group, respectively. The ST interval was also significantly $(p<0.001)$ higher in the stenosis group. Pretreatment for 18 days and post stenosis treatment for 28 days with cyclodextrin-garcinol complex $(20 \mathrm{mg} / \mathrm{kg})$ lowered QT and ST intervals significantly $(\mathrm{p}<0.05)$, compared with the stenosis group (Table 4 and Figure 2).

\section{Effect of cyclodextrin-garcinol complex $(20 \mathrm{mg} / \mathrm{kg})$ on heart weight/body weight ratio}

Heart to body weight ratio was significantly $(p<0.001)$ higher in the stenosis group compared with the control group and Sham group. Pretreatment for 18 days and post stenosis treatment for 28 days with cyclodextrin-garcinol complex $(20 \mathrm{mg} / \mathrm{kg})$ resulted in significant $(\mathrm{p}<0.001)$ reduction in the ratio of heart weight/body weight as compared with stenosis group (Table 5).

\section{Effect of cyclodextrin-garcinol complex $(20 \mathrm{mg} / \mathrm{kg})$ on Left ventricular weight/Body weight ratio}

Left ventricular to body weight ratio was significantly $(p<0.001)$ higher in the stenosis group compared with the control group and sham group Pretreatment for 18 days and post stenosis treatment for 28 days with cyclodextrin-garcinol complex $(20 \mathrm{mg} / \mathrm{kg})$ resulted insignificant $(\mathrm{p}<0.001)$ reduction in the ratio of left ventricular weight/body weight of the rats compared to stenosis group (Table 6).

\section{Effect of cyclodextrin-garcinol complex on myocardial MDA levels}

Myocardial MDA concentration was significantly $(\mathrm{p}<0.001)$ higher in the stenosis group compared with the control group and sham group Pretreatment for 18 days and post stenosis treatment for 28 days with cyclodextrin-garcinol complex $(20 \mathrm{mg} / \mathrm{kg})$ resulted in lowering MDA concentration significantly $(p<0.01)$ in the cyclodextrin-garcinol complex $(20 \mathrm{mg} / \mathrm{kg})$ group compared with the stenosis group (Table 7). 
1) ECG of rat from Sham group on 44thday shows the normal response

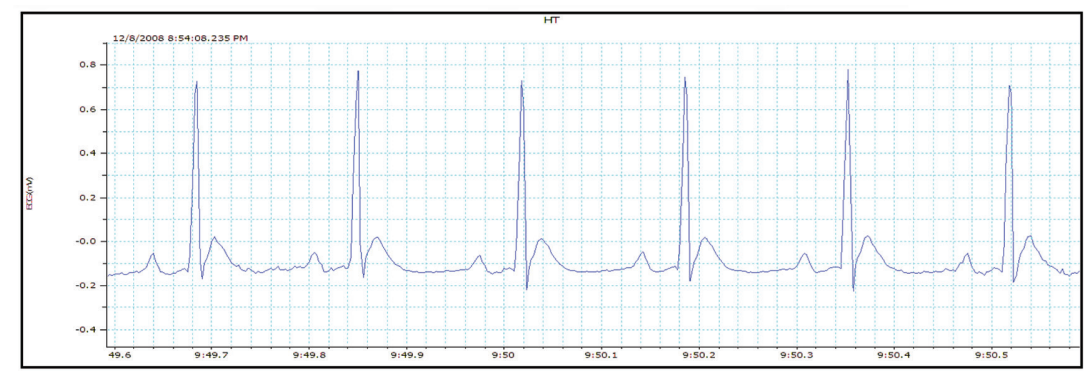

2) ECG of rat from aortic stenosis group on 44thday shows the prolongation in QT and ST segment of the ECG.

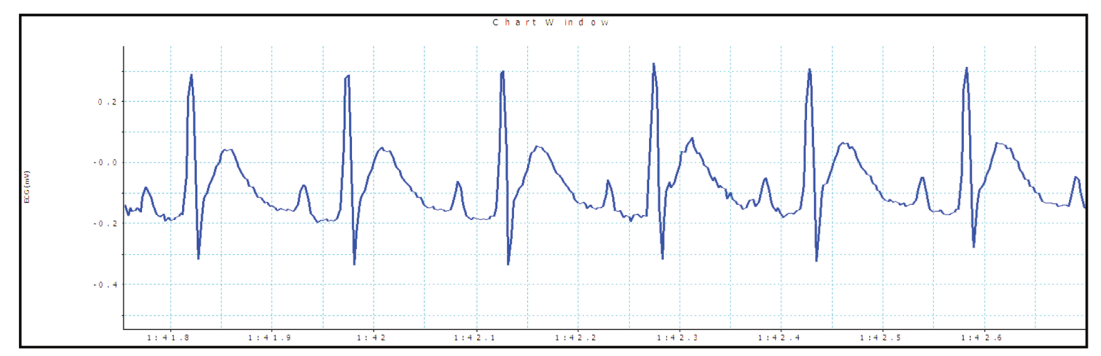

3) ECG of rat from cyclodextrin-garcinol group on 44thday shows the reversal of the prolongation in QT and ST segment of the ECG.

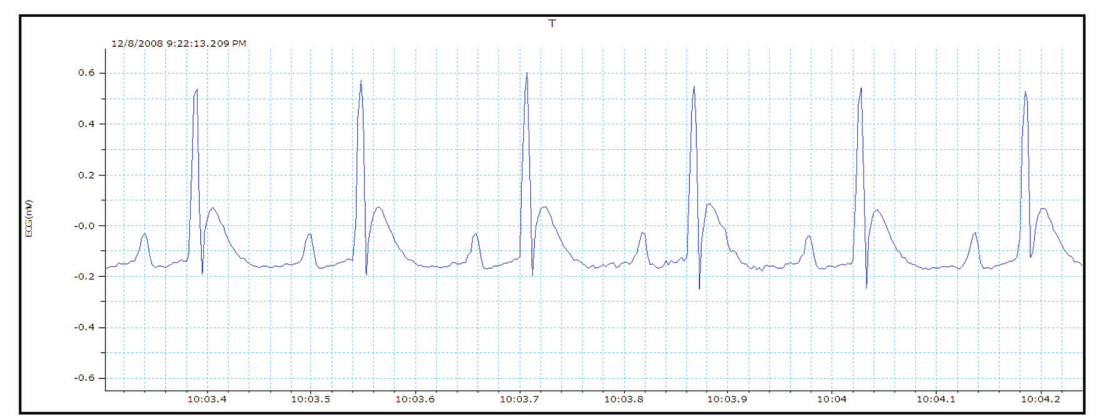

Figure 2 Effect of cyclodextrin-garcinol complex $(20 \mathrm{mg} / \mathrm{kg})$ on QT and ST interval of male Wistar rats in experimentally induced cardiac hypertrophy by rat aortic stenosis

\section{Effect of cyclodextrin-garcinol complex on myocardial GSH levels}

Myocardial GSH concentration was significantly $(\mathrm{p}<0.001)$ lower in the stenosis group compared with the control group. Pretreatment for 18 days and post stenosis treatment for 28 days with cyclodextrin-garcinol complex $(20 \mathrm{mg} / \mathrm{kg})$ resulted in significantly $(\mathrm{p}<0.05)$ higher myocardial GSH concentration in the cyclodextrin-garcinol complex (20 $\mathrm{mg} / \mathrm{kg}$ ) group compared with stenosis group (Table 7).

\section{DISCUSSION}

Haemodynamic, sustained pressure overload will override these adaptive mechanisms, leading to cardiac hypertrophy, decreased contractile function, and the development of heart failure. The literature showed in vivo studies that, the molecular pathways involved in cardiac hypertrophy can be specifically by exposing rats to either biomechanical stress through transaortic constriction of the aorta. Although left ventricular hypertrophy is the most important compensation mechanism in chronic pressure overload, it has frequently been associated with heart failure and death. ${ }^{19}$ It occurs because the hypertrophied myocardium presents structural changes that lead to cardiac remodeling, such as a disproportional increase in the myocytes component compared to vascular component.

One of the consequences is an imbalance between oxygen supply and consumption, which causes myocytes necrosis, apoptosis, and abnormal collagen accumulation. Fibrosis also occurs as a direct consequence of activation of the renin-angiotensin system in the myocardium. ${ }^{20}$ The stimuli for developing cardiac remodeling also include mechanical and biochemical factors which, acting on receptors, ionic channels, and integrin present in the sarcolemma membrane. ${ }^{21}$ trigger cytosolic biochemical signals provoking increased protein synthesis and changes in gene expression. ${ }^{22}$ All these alterations lead to a worsening of cardiac function, associated with diminished contractility.

In the present investigation the cardiac hypertrophy was confirmed by the heart weight / body weight ratio and left ventricular weight /body weight ratio in rats. In the stenosis group significant increase in both the ratios was observed. Pretreatment for 18 days and post stenosis treatment for 28 days, resulted in the significant reduction in both ratios. Result thus indicated that complex $(20 \mathrm{mg} / \mathrm{kg})$ possessed anti-hypertrophic effect. Aortic stenosized rats showed decrease in heart rate. ${ }^{23}$ These results were consistent with the earlier studies where it was hypothesized that aortic stenosis condition induced reactive oxygen species formation causes disturbance in calcium homeostasis. ${ }^{24}$ This could lead to a reduction in heart rate because decrease in intracellular calcium reduced excitability of pacemaker cells in the sino atrial node and other cells in the cardiac conduction system.

In recent years, electrical remodeling has emerged as an important pathophysiological mechanism in the development of mechanical dysfunction, pump failure and sudden death. When detected by electrocardiography, cardiac hypertrophy and heart failure are commonly associated with the development of QT and ST interval prolongation or dispersion and life threatening arrhythmias. ${ }^{25,26}$ Clinical studies suggest that $50 \%$ of sudden deaths associated with heart failure are attributable to ventricular tachycardia or fibrillation, the other half being coupled to bradyarrhythmias or electromechanical dissociation. ${ }^{27}$ The electrocardiographic parameter from 
this study indicated that aortic stenosis significantly prolonged QT and ST intervals as compared to sham group, while treatment of cyclodextrin-garcinol complex resulted in significant reduction of the QT and ST interval prolongation.

In aortic stenosized rats significant increase in MDA content in cardiac tissues as well as highly significant reduction in cardiac tissue levels of protective biological antioxidant enzymes like GSH were compared to that of the sham group indicating oxidative stress. These results correlate with previous studies which have demonstrated the involvement of oxidative stress and lipid peroxidation in aortic stenosis induced cardiac hypertrophy. ${ }^{28}$ The treatment with cyclodextrin-garcinol complex $(20 \mathrm{mg} / \mathrm{kg})$ significantly increased the GSH levels and decrease the MDA level, that producing a cardioprotective effect. Haemodynamic changes revealed that the aortic stenosis group showed significant increase in MABP, systolic and diastolic $\mathrm{BP}$, as compared with sham group. While treatment of cyclodextrin-garcinol complex $(20 \mathrm{mg} / \mathrm{kg})$ showed non-significant decrease in the MABP, systolic blood pressure and diastolic blood pressure.

\section{CONCLUSION}

It is concluded that cyclodextrin-garcinol complex $(20 \mathrm{mg} / \mathrm{kg})$ protected the haemodynamics of stenosized heart of rats, restoration of normal function of stenosized heart is reflected by minimal (non significant) response change in MABP, Systolic BP, and Diastolic BP. It offered significant protection against cardiotoxicity and cardiac hypertrophy as well as reduced myocardial injury by reduction of lipid peroxidation and preservation of endogenous antioxidants in rat heart.

\section{ACKNOWLEDGEMENTS}

The authors acknowledge Dr. S.S. Kadam, Chancellor, Bharati Vidyapeeth Deemed University, Dr. K.R. Mahadik, Principal, Poona College of Pharmacy for keen interest for this work. We thank to Sunil Bhaskaran of Indus Biotech Private Limited, Pune, for financial support and Dr. Manish Sinha for their help in writing of manuscript.

There is no conflict of interest among the authors.

\section{REFERENCES}

1. Mosterd A, Hoes AW, de Bruyne MC, Deckers JW, Linker DT, Hofman A, GrobbeeDE.Prevalence of heart failure and left ventricular dysfunction in the general population, TheRotterdam Study.Eur Heart J, 1999; 20: 447-455.
2. Patten, R D, Hall-Porter M R. Small animal models of heart failure: development of novel therapies, past and present. Circ Heart Fail, 2009; 2: 138-144.

3. Weinberg, E. O. et al. Angiotensin-converting enzyme inhibition prolongs survival and modifies the transition to heart failure in rats with pressure overload hypertrophy due to ascending aortic stenosis. Circulation, 1994; 90: 1410-1422.

4. Opie LH, Commerford PJ, GershBJ, Pfeffer MA. Controversies in ventricular remodeling. Lancet, 2006; 367: 356-367.

5. Drazner M H.The progression of hypertensive heart disease. Circulation, 2011;123: 327-334.

6. Feldman AM, Weinberg EO, Ray PE,Lorell BH. Selective changes in cardiac gene expression during compensated hypertrophy and the transition to cardiac decompensationin rats with chronic aortic banding. Circ Res,1993;73: 184-192.

7. Dostal DE. The cardiac renin-angiotensin system: novel signaling mechanisms related to cardiac growth and function. RegulPept, 2000; 91: 1-11.

8. Sadoshima J, Izumo S. Molecular characterization of angiotensin II-induced hypertrophy of cardiacmyocytes and hyperplasia of cardiac fibroblasts. Critical role of the AT1 receptor subtype. Circ Res, 1993; 73: 413-423.

9. Sadoshima J, Xu Y, Slayter HS, Izumo S. Autocrine release of angiotensin II mediates stretch-induced hypertrophy of cardiac myocytesin vitro. Cell, 1993; 75: 977-984.

10. Sadoshima J, Izumo $S$. The cellular and molecular response of cardiac myocytes to mechanical stress.Annu Rev Physiol. 1997; 59:551-71.

11. Xu R, Lin F, Zhang S, Chen X, Hu S,Zheng Z. Signal pathways involved in reverse remodeling of the hypertrophic rat heart after pressure unloading. Int J Cardiol, 2010; 143: 414-423,

12. Van Berlo JH, Elrod JW, Aronow BJ, Molkentin JD. Serine 105 phosphorylation of transcription factor GATA4 is necessary for stress-induced cardiac hypertrophy in vivo. ProcNatlAcadSci USA, 2011; 108: 12331-12336,

13. A complex of garcinol, cyclodextrin and method there of EP 2649035 A1, WO 2012/076988 PCT/IB2011/050316 3.

14. Liu L, Guo Q-X. The driving forces in the inclusion complexation of cyclodextrins. J InclPhenomMacrocyclChem, 2002; 42:1-14

15. Cordelia JB, Mauricio R, Robert S, Susan SS, and David WT. Cardiac response to pressure overload in 129S1/SvImJ and C57BL/6J mice temporal and background dependent development of concentric left ventricular hypertrophy. Am J Physiol Heart CircPhysiol, 2007;292:2119-2130.

16. Complex of garcinol, cyclodextrin and method there of United States Patent Application 20150196669, 07/16/2015

17. Slater TF, Sawyer BC. The stimulatory effects of carbon tetrachloride and other alogenoalkanes or peroxidative reactions in rat liver fractions in vitro.Biochem J, 1971; 123: 805-14.

18. Moron MS, Depierre JW, Mannervik B. Levels of glutathione, glutathione reductaseand glutathione S-transferase activities in rat lung and liver. BiochemicBiophys ACTA, 1979; 582: 67-78.

19. Schmieder RE, Messerli FH. Is the decrease in arterial pressure the sole factor for reduction of left ventricular hypertrophy, Am J Med1992; 92: 28-34.

20. Colucci WS. Molecular and cellular mechanisms of myocardial failure.Am J Cardiol,1997; 80: 15L-25.

21. Borg TK, Burgess ML. Holding it all together: organization and functions of the extracellular matrix of the heart. Heart Failure, 1993; 8: 230-8.

22. Dzau VJ. Autocrine and paracrine mechanisms in the pathophysiology of heart failure. Am J Cardiol,1992; 70: $4 \mathrm{C}-11$.

23. OkoshiK,RibeiroHB,Okoshi MP, MatsubaraBB, Goncalves G and Barros RC.Improved Systolic Ventricular Function With Normal Myocardial Mechanics in Compensated Cardiac Hypertrophy.Jap Heart J, 2004; 45: 647-656. 
24. Xuwan Liu, Zhou H, Ye H, Li J. Atorvastatin lowers plasma matrix metalloproteinasein patients with acute coronary syndrome. ClinChem 2002;50:750-753.

25. Kulan K, Ural D, Komsuoglu B, Agacdiken A, Goldeli O and Komsuoglu SS.Significance of QTcprolongation on ventricular arrhythmias in patients with leftventricular hypertrophy secondary to essential hypertension. Int J Cardiol,1998; 64: 179-184.

26. Pogwizd SM and Bers DM. Cellular basis of triggered arrhythmias in heart failure. Trends Cardiovasc Med, 2004; 14: 61-66.

27. Janse MJ. Electro physiological changes in heart failure and their relationship to arrhythmogenesis. Cardiovasc Res,2004;61: 208-217.
28. Zijianxie, Peter Kometiani, Jiangliu, Jie Li, Joseph I. Shapiro, and Amir Askari. Intracellula reactive oxygen species mediate the linkage of $\mathrm{Na}+/ \mathrm{k}+$ ATPase to hypertrophy and its marker genes in cardiac myocytes, J Biol Chem, 1999;274(27): 19323-19328.

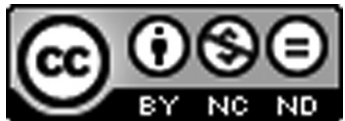

This work is licensed under a Creative Commons Attribution-Non Commercial-No Derivatives 4.0 International License. To view a copy of this license, visit http://creativecommons.org/licenses/by-nc-nd/4.0/ 